\title{
Influence of working conditions on the economy of an agricultural enterprise
}

\author{
Yuri Shirokov ${ }^{*}, 1$ and Valery Tikhnenko ${ }^{1}$ \\ ${ }^{1}$ Russian state agrarian University-Moscow agricultural Academy K. A. Timiryazeva, 127550, \\ Timiryazevskaya str., 49, Moskow, Russia
}

\begin{abstract}
The article deals with the problems of increasing the economic efficiency of agricultural enterprises by improving working conditions, reducing the level of exposure to harmful and dangerous production factors. The purpose of the article is to analyze methodological approaches to forecasting possible economic losses of agricultural enterprises due to the presence of harmful or dangerous working conditions and to develop organizational and management solutions to reduce these losses. Economic services of agricultural enterprises need to have a methodology for assessing real economic losses due to unfavorable working conditions at enterprises, which will give employers an understanding that the costs of labor protection and safety not only pay off, but also give a significant economic effect and contribute to improving the profitability of production and allow them to make informed management decisions. It is shown that forecasting economic damage from occupational diseases and industrial injuries, accidents is a complex task, but it is quite solvable on the basis of the procedure for assessing and managing occupational risks and applying known patterns of crop losses or animal productivity due to violations of agrotechnical deadlines or animal maintenance regime due to the absence of an injured employee at the workplace.
\end{abstract}

\section{Introduction}

According to the International labour organization, economic losses caused by accidents and occupational diseases account for about 3-4\% of GDP in industrialized countries and create significant economic problems for farmers [1-2].

In the normal mode of operation, the company's economy loses compensation for working in harmful and (or) dangerous working conditions due to non-compliance of working conditions with regulatory requirements. Specific gravity $[(\mathrm{Li})$ of hazardous working conditions. for certain types of economic activity (at the end of 2019), according to the Federal state statistics service, $35.3 \%$ were among men and $27.3 \%$ among women. These expenses amount to 7951858 thousand rubles. This amount includes expenses for annual additional leave of 1149617 thousand rubles, increased labor remuneration-1943771 thousand rubles, medical and preventive nutrition-4928 thousand rubles, purchase of milk

\footnotetext{
* Corresponding author: shirokov001@mail.ru
} 
or other equivalent food products - 196420 thousand rubles, medical examinations 734194, purchase of workwear, safety shoes and other personal protective equipment 6177760 thousand rubles. But even more significant and, unfortunately, impossible to accurately assess, are the losses from reduced labor productivity due to the presence of harmful and dangerous factors in the workplace.

In Russia, the situation with economic losses from unfavorable working conditions does not differ from the world. In 2019. according to the Department of occupational risk insurance of the social insurance Fund of the Russian Federation, there were 39,533 insured events for 50 million insured employees, $12 \%$ of accidents were severe, $4 \%$ were fatal, and $74 \%$ were mild. $10 \%$ were recorded as occupational diseases. The average loss of working time to recover from injuries was about 49 days. It is easy to calculate that the country's economy lost 1 million 937 thousand working days just because of the lack of workers in the workplace

The desire to increase the economic efficiency of agricultural production leads to the creation of more and more advanced and expensive technologies, machines and equipment. Naturally, the higher the energy saturation of machines, the higher their productivity, the more expensive each hour of their work, the more their efficiency depends on the operator's performance [3]

Therefore, the economic services of enterprises need to improve the methodology for assessing real economic losses due to unfavorable working conditions in agricultural enterprises, and employers need reliable information about potential economic losses due to the presence of harmful and dangerous production factors in the workplace and the cost effectiveness of labor protection and safety, their contribution to improving the profitability of production.

Available techniques to determine the damage caused to the enterprise and society, morbidity, injuries, loss of productivity due to worker exposure to adverse production factors, do not always take into account the specificity of agricultural production, for example, crop losses due to lost of sowing dates due to the illness of a tractor-driver or loss of harvest due to delays in harvesting due to injury combiner, the loss of yields due to the poor health of the milker, etc[4-6].

Purpose of the article: analysis of methodological approaches to assessing losses of agricultural enterprises due to unfavorable working conditions and development of organizational and management solutions to reduce these losses.

\section{Analysis of working conditions in agriculture and their impact on performance}

The methodological basis of the work is the analysis of the results of research on the state of working conditions in the main branches of agriculture and methodological approaches to assessing the economic losses of agricultural enterprises due to the presence of harmful and dangerous factors in the workplace.

\subsection{Working conditions in the main branches of agriculture}

At the end of 2019, 33.8\% of Russian agricultural workers were employed in harmful or dangerous working conditions. Feature of agriculture: almost all enterprises are designed to ensure high profitability and create optimal conditions for biological objects: animals, birds, plants, fungi, etc., but do not take into account the provision of acceptable conditions for service personnel who have been forced to perform labor functions in unfavorable conditions for humans for decades. The health of agricultural workers is negatively affected 
not only by hard physical labor, but also by unfavorable microclimatic conditions, various chemical and biological substances, and poisons directly in a number of technological operations [7-9].

We have conducted research on the state of working conditions of operators at the pig complex of JSC "BIO-M of the Bryansk region. It is established that the parameters of the microclimate in the livestock premises of the enterprise do not meet sanitary and hygienic standards. The relative humidity in the premises exceeds the standard for a person $(75-90$ $\%$ ), the temperature does not reach the standard values: $\left.8-18^{\circ} \mathrm{C}\right)$. The noise level during the distribution of feed, processing of premises and animals (for example, during vaccinations) reaches $86-96 \mathrm{~dB}$. The maximum sound pressure occurs at high frequencies up to $8000 \mathrm{~Hz}$.

It was found that the content of ammonia in the morning hours is more than $20 \mathrm{mg} / \mathrm{m} 3$, hydrogen sulfide - $10 \mathrm{mg} / \mathrm{m} 3$, and carbon dioxide $0.3-0.4 \%(5490-9150 \mathrm{mg} / \mathrm{m} 3)$. that exceed the permissible limits according to GOST 12.1.005-76. Along with this, the air of the working area is filled with organic dust formed during the distribution of feed and the introduction of litter, which contains feed protein and vitamin supplements, not infrequently medicines, particles of animal epithelium and wool, products of fungi, etc. This creates prerequisites for both colds and occupational diseases. The data are consistent with the results of other researchers [5,9].

Moreover, along with microclimatic factors that do not meet sanitary and hygienic standards, a number of other harmful factors contained in the air of the working area affect employees of pig-breeding enterprises (and cattle farms, poultry farms). According to the FAO, $9 \%$ of carbon dioxide, $37 \%$ of methane, and $70 \%$ of ammonia entering the Earth's atmosphere are produced in animal husbandry. But before they are released into the atmosphere, these gases are contained in the air of the working area and affect the organisms of pig operators, cattle breeders, machine milking operators, poultry houses, etc. Therefore, livestock workers are constantly in conditions that do not meet sanitary and hygienic requirements during the working day and throughout their working life, usually for more than 35 years.

Long-term research of medical institutions has accumulated a sufficient level of knowledge about the relationship of specific health disorders with harmful factors in the workplace, including agricultural workers [10,11]. Thus, ammonia (hazard class 4), even in small concentrations, leads to the development of pathology on the part of various human organs. Even if the air of the working zone, the content of ammonia close to the MPC (In the air of working zone of production areas MPC of ammonia $20 \mathrm{mg} / \mathrm{m} 3$ - GN 2.2.5.68698), this leads to a decrease in the bioelectric activity of the brain, anosmia, reduced level of ascorbic acid in the blood, the slow excretion of urea. There are violations of the functions of higher nervous activity, hypotonic reactions, tachycardia, even if the ammonia content in the air of the working area is within $10 \mathrm{mg} / \mathrm{m} 3$.

Therefore, it is quite natural that many livestock and poultry workers develop diseases of the respiratory system $-17.8 \%$, gastrointestinal tract- $14.7 \%$, nervous system and sensory organs-8.2\%, musculoskeletal system $-5.8 \%$, kidneys and urinary tract $-5.5 \%$. Employees of protected ground enterprises (greenhouses) are in long-term contact with pesticides against the background of high humidity and temperature (heating microclimate) and high physical activity. Work on the second day after the use of fungicides and insecticides can cause intense damage to open areas of the body of workers (hands, shins, neck, mucous membranes of the eyes and other organs).

Normally used personal protective equipment does not ensure the safety of employees. As it turned out, toxic chemicals quickly penetrate the inner side of protective equipment. As a result, greenhouse workers are most characterized by diseases of the circulatory, respiratory, urinary and digestive systems due to exposure to pesticides, a serious increase 
in the frequency of chromosomal aberrations in the peripheral blood lymphocytes of protected ground workers was detected. The effect of a chemical agent on the body may not appear for a long time. Only years later, a person develops chronic inflammatory diseases of the liver, kidneys, pancreas, endocrinopathy, cancer, etc.

The situation with the working conditions of tractor drivers working in the field is no better [8.11]. Tractor drivers in agriculture aged 50 years and older are 2 times more likely to get sick compared to similar workers in other sectors of the economy. Studies in previous years have shown that tractor drivers under the age of 45 in $55 \%$ of cases, and in 50 years in $80 \%$ of cases suffer from chronic diseases.

The level of General injuries in agriculture is also one of the highest among all types of economic activity and exceeds the average value in Russia by 1.5-1.7 times. Female mortality in animal husbandry is 2.5 times higher than in other sectors of the economy.

\section{The impact of working conditions on performance and productivity}

Let's take only three main factors of the production environment, the harmful effects of which can significantly affect both the level of injuries and occupational diseases, as well as fatigue during work and reduced productivity: workplace lighting, workplace noise, and microclimate parameters [12].

\subsection{Influence of the light environment on labor productivity}

Rational lighting provides psychological comfort, helps reduce visual and General fatigue, and reduces the risk of occupational injuries. In various types of industrial activities, the number of accidents related to lighting in one way or another is on average $30-50 \%$ of the total number. In rough work, about $1.5 \%$ of serious fatal injuries occur due to low light conditions. Eye injuries in these jobs account for 7.8 to $31.1 \%$ of the total number of accidents, with 18 to $25 \%$ of eye injuries associated with poor lighting in the workplace.

Research and production practice show the positive impact of a properly designed lighting system on health and labor productivity. Thus, solar lighting increases labor productivity by up to $10 \%$, and the creation of rational artificial lighting - up to $13 \%$. When performing rough visual work, a $10 \%$ decrease in performance is observed at a brightness 60 times lower than the absolutely optimal level, at which the processes of biochemical and retinomotor adaptations are mobilized (retinomotor reaction of photoreceptors - mechanical processes in the retina associated with the rearrangement of the relative location of receptors(rods and cones) and melanin granules in accordance with the light level ). Large objects can be distinguished at very low brightness, and, of course, labor productivity will decrease by $70-80 \%$.

\subsection{Effect of noise on humans}

Noise at work weakens the attention of the worker, increases energy consumption with the same physical activity, slows down the speed of mental reactions. Under the influence of systematic noise, labor productivity in some cases decreases by up to $66 \%$, and the number of errors in calculation work increases by more than $50 \%$. Noise is also a cause of impaired memory, attention, visual acuity, and sensitivity to warning signals given by personnel serving in-plant transport (forklifts, electric cars, overhead cranes, etc.), which can cause an accident. 
The human hearing organ is a complex system. The inner ear has about 25,000 cells that respond to sound. In total, a person can distinguish between 3-4 thousand sounds of different frequencies. The most characteristic vegetative reaction to noise is a narrowing of the capillaries of the skin and mucous membranes, which occurs already at the sound level of 60-70 dBA and leads to a violation of peripheral blood circulation.

The biological effect of noise depends on the following factors:

- intensity,

- duration of exposure,

- frequency spectrum (high frequencies are the most dangerous),

- time characteristics ( pulse noise is the most dangerous).

Adverse effects of acoustic vibrations lead to headaches, dizziness, memory loss, increased fatigue and, as a result, increased occupational risks and reduced productivity. Excessive noise in the body reduces the immune barrier and increases the frequency of diseases, and the most diverse - from colds to gynecological. Studies show that in noisy enterprises, the incidence rate is $20 \%$ higher than the average [9].

\section{Influence of microclimate parameters on the human body and its performance}

Microclimate parameters have a direct impact on a person's well-being and performance. It is established that at an air temperature of more than 30 degrees. human performance begins to fall. For example, when the temperature increases from 26 to $29 \mathrm{Co}$, labor productivity decreases by $13 \%$, and when it increases to $33 \mathrm{Co}$, it decreases by $35 \%$. But it is in such conditions that operators in animal husbandry, greenhouses and mushroomgrowing enterprises have to work.

When the indoor air temperature is high, the skin's blood vessels expand. In this case, there is an increased blood flow to the surface of the body, and heat transfer to the environment increases significantly. Prolonged exposure to high temperatures, especially in combination with high humidity, can lead to a significant accumulation of heat in the body and the development of overheating of the body above the permissible level - hyperthermia - a condition in which the body temperature rises to 38-40 degrees., there is a headache, weakness, nausea, vomiting. The pulse and respiratory rate are accelerated, and the content of residual nitrogen and lactic acid in the blood increases. There is pallor, blue skin, dilated pupils, sometimes there are convulsions, loss of consciousness.

At a low temperature, a significant speed and humidity of the air, hypothermia occurs. Skin vessels narrow, blood flow to the surface of the body slows down, and the return of heat by convection and radiation decreases. Blood supply at low temperatures can be 20-30 times less than at high temperatures. In the fingers, the blood supply can change even 600 times At the initial stage of exposure to moderate cold, there is a decrease in the respiratory rate, an increase in the volume of inspiration. With prolonged exposure to cold, carbohydrate metabolism changes. The increase in metabolic processes with a decrease in temperature by 1 Celsius degree is $10 \%$, and with intensive cooling, it can increase by 3 times compared to the level of the main exchange.

The situation needs to change. To do this, employers must have a clear understanding of the amount of economic losses incurred by the company due to the presence of harmful and dangerous production factors in the workplace, which lead to additional costs and reduce the profitability of production. and about the measures that will allow you to bring working conditions to standard levels.

\section{Methodological features of calculating the increase in labor productivity due to increased efficient}


Economic losses of agricultural enterprises due to the presence of a significant number of jobs in harmful or dangerous working conditions consist of losses in labor productivity, losses for various types of compensation and additional payments to funds (social insurance and pension), and losses due to accidents and diseases of employees, including professional ones. If the first group of losses for the employer is obvious and mandatory, the second is probabilistic and it is important that this probability is reduced to zero. This is what the concept of "zero injuries" focuses employers on. But its implementation is directly related to the solution of the first task: elimination of harmful and dangerous factors in the workplace [13].

The main sources of economic efficiency from measures to improve labor protection, in addition to reducing or completely eliminating the above costs, is the increase in labor productivity due to:

-improving human performance as a result of fatigue caused by adverse working conditions, reducing or completely eliminating in-shift downtime, etc.This is especially important during the sowing season, when any delay leads to losses of potential crops and harvesting operations, when the already grown crop is lost;

- reducing the labor intensity of products due to the reduction of unproductive labor costs caused by adverse conditions;

-increasing the effective working time Fund as a result of reducing the loss of working time due to temporary disability due to injuries and diseases associated with unfavorable working conditions $[6,14]$.

There is a close relationship between the integral assessment of labor severity and the level of working capacity: the higher the integral assessment of labor severity, the lower the level of working capacity falls and, consequently, fatigue increases, and Vice versa. Therefore, knowing the indicator of labor severity $(\mathrm{Gl})$, the value of working capacity (O) under these working conditions can be determined using the formula obtained empirically (A. Mustafina):

$$
\mathrm{O}=100-\left(\mathrm{G}_{1}-15,6\right) / 0,64
$$
units;

where $\mathrm{O}$ is the indicator of working capacity under given working conditions, relative

Gl - integral indicator of labor severity, formed under the same conditions, points; 15.6 and 0.64 - regression coefficients.

The possible increase in labor productivity due to increased efficiency is determined by the formula:

$$
\mathrm{I}_{1}=\left(\mathrm{O}_{2} / \mathrm{O}_{1}-1\right) \times 100 \times \mathrm{K}
$$

where $\mathrm{I}_{1}$ is a possible increase in labor productivity, \%;

$\mathrm{O}_{1}$ and $\mathrm{O}_{2}$ - performance indicators before and after improvement of working conditions, relative units;

$\mathrm{K}$ - coefficient that takes into account the possible increase in labor productivity as a result of increased efficiency.

The economic result (Er) is characterized by the prevented economic damage from accidents, injuries and occupational diseases, the economic effect of measures to improve hygienic, technical and social working conditions. 


\section{Methodological bases for calculating economic indicators of labor protection and safety measures}

If accidents occur at the enterprise, new cost items are added to these expenses, which are taken into account in sufficient detail in the methods for assessing the economic losses of agricultural enterprises from accidents and occupational diseases $[5,6,12]$.

Material losses of an enterprise as a result of an accident are divided into direct and indirect. Direct losses include a surcharge for the time of disability due to injury and the cost of treatment. Indirect losses consist of the loss of working time of other employees and employees of the production division administration; damage to property; loss of part of investments; loss of labor productivity, etc. Indirect losses, according to some authors, are 4-6 times higher than direct losses. Damage to the enterprise where the accident occurred. it can be estimated by calculating and adding up potential losses and additional expenses, payments and surcharges using the formula 3 :

$$
E d=\sum(D i+E k+P r+S d)
$$

where D1 - losses due to downtime of technological equipment in case of staff disability;

D2 - $\bullet$ loss of revenue by the enterprise due to a decrease in output;

D3 -• losses from reduced productivity after the victim returns to production;

E1 -- salary expenses for employees who participated in the rescue of the victim and first aid, in the elimination of the consequences of an accident or accident

E2 expenses related to the selection and additional training of a worker to replace the victim;

E3-- expenses related to the involvement of experts, technical inspection, specialized laboratories, etc. in the investigation of an accident (accident);

P1 - payment of salary to the victim for the time that he did not complete on the day when the accident occurred;

$\mathrm{S} 1$ - additional payment of the difference when transferring the victim to a temporary lower-paid job until the recovery of health or retirement;

P2 - payment of severance pay to the victim when transferring him to disability or to the victim's family in the event of his death;

-P3 - payment of a one-time benefit to the victim or his family from the company's Fund;

D4 - other indirect losses (expenses for lawyers, fines, etc.);

B3 - increase in the amount of the insurance premium"

in the event of an accident:

D5 - loss of property (breakdown of machinery and equipment, loss of products);

E4 - expenses for the restoration and repair of equipment, vehicles, etc.;

P4 - additional payment for overtime work related to the elimination of the accident and its consequences, as well as the replacement of the victim.

As can be seen from the list of mandatory items of expenses for eliminating the consequences of accidents and accidents, economic losses can be quite significant. This damage can be assessed in advance, before possible incidents, either by expert analysis or by probabilistic calculation when assessing professional risks, which must be performed at each enterprise from January 2020. Since risk is a combination of probability and severity of consequences, the criticality of risk $(\mathrm{R})$ is determined by the probability of harm (Pr) multiplied by the severity of its consequences $(\mathrm{G})$ :

$$
\mathrm{R}=\operatorname{Pr} \mathrm{x} \sum \mathrm{G}
$$


That is why all risk assessment methods are based on consistently identifying potential hazards associated with the object of assessment ("What can happen?"), identifying the probability of their occurrence ("What is the probability that this will happen?") and assessing possible consequences ("What can be the consequences?"). That is, regardless of the method used, we get an answer to each of the three key questions stated in "ICH guideline Q9 on quality risk management CHQ9". The choice of the damage indicator used for risk assessment depends on the goals (providing reporting data, identifying sources of risk, choosing options for effective risk management, etc.), resources, amount of information, features of the tasks to be solved, and other factors.

\section{Methodological differences in calculating damage from temporary disability of employees}

Agriculture, in which the main objects of human labor activity are living organisms - plants and animals, has differences that directly affect the methodological features of assessing economic losses due to accidents and occupational diseases. In agriculture, the failure of the operator due to fatigue, illness, accident is not only the loss of working days, it is not only the downtime of expensive equipment, but, most importantly, in conditions of shortage of personnel and lack of replacement workers, agricultural deadlines in crop production are disrupted, and biological rhythms in animal husbandry are disrupted. As a result, this leads to irreplaceable losses of agricultural enterprises.

The peculiarity of crop production is that delaying the completion of a number of basic operations (sowing, harvesting) significantly affects the reduction of yield or loss of the grown crop, for example, due to the shedding of dry grain or breaking off of a heavy ear. Moreover, large, high-quality grain is showered, while small and puny grain is preserved. It should be taken into account that losses from shedding due to delayed harvesting periods also depend on the resistance to shedding of the crop variety, the possibility of using drugs that minimize shedding, for example, on rapeseed. Thus, the loss of winter wheat grain is 47 days after the full ripeness of the grain 1, 4cn/ha, 8-10 days - 3cn/ha, 11-13 days - 4, $9 \mathrm{cn} / \mathrm{ha}, 14-16$ days $-5 \mathrm{cn} / \mathrm{ha}, 17-20$ days $-8,5 \mathrm{cn} / \mathrm{ha}$. The generalized dependence of crop losses on the duration of harvesting and grain humidity in the ear is shown in the figure.

Economic losses from equipment downtime due to the combine operator's illness (in the absence of a replacement combine operator) can be calculated using the following formula:

$$
C=B(V i x P \kappa \times T o) K i
$$

Where $\mathrm{B}$ is the cost of a crop unit, $\mathrm{RUB} / \mathrm{C}$;

$\mathrm{Vi}$ - biological yield of the $\mathrm{i}$ - th crop, $\mathrm{C} / \mathrm{ha}$;

$\mathrm{RC}$-productivity of the $\mathrm{K}$-th machine, ha/hour;

To - the total time of delay in harvesting for the calendar period of harvesting, hour;

$\mathrm{Ki}$ - loss coefficient, $\mathrm{C} / \mathrm{ha}$. 


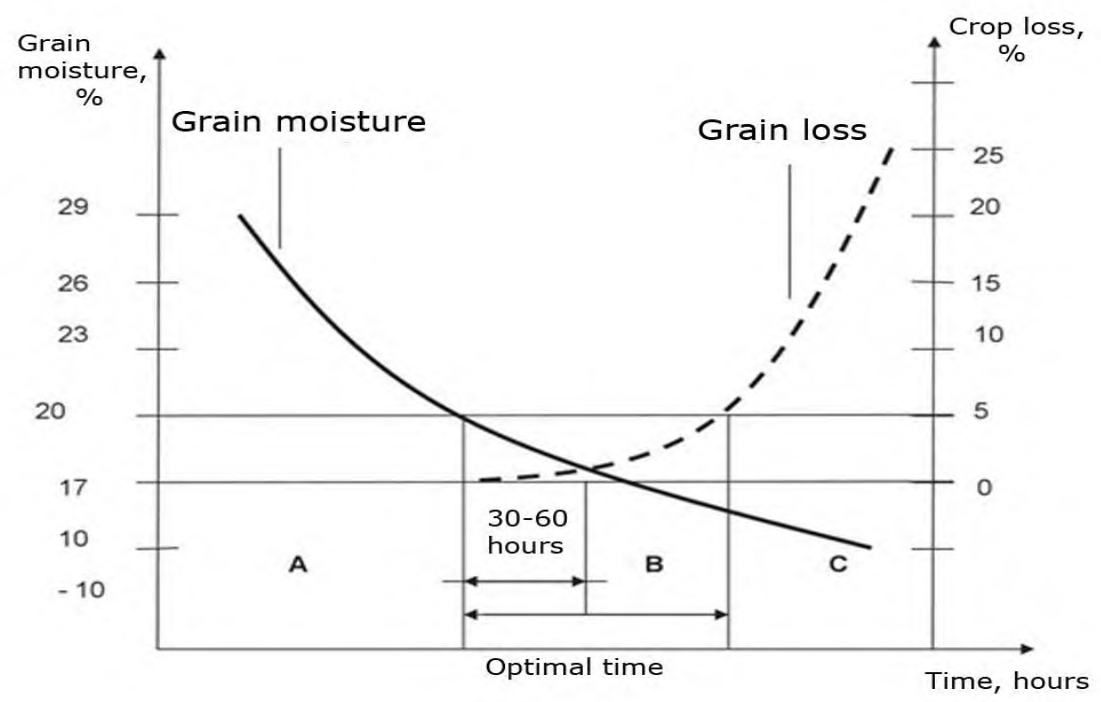

Fig. 1. Dependence of crop losses due to grain shedding on the duration of harvesting and grain humidity in the ear (V. Novikov)

D. Hunt from the University of Iowa proposed a coefficient K (dimension 1/year), which allows you to take into account the decrease in yield due to the delay of the operation for 1 hour against the optimal technological period. According to hunt, the K coefficient for corn and soybean crops is 0.0003 , basic tillage is 0.00005 , cultivation is 0.0002 , grain harvesting is 0.0003 , soybean harvesting is 0.0007 , hay harvesting is 0.0005 , and silage harvesting is 0.0001 .

$$
\mathrm{C}=\mathrm{K} \times \mathrm{A} \times \mathrm{V} \times \mathrm{Y}
$$

where $\mathrm{A}$ is the land area, ha;

$\mathrm{V}$ - expected (lossless) yield;

$\mathrm{B}$ - the cost per unit of crop.

The total losses in this case are:

$$
C z=C x T o
$$

where Is the total number of hours of delay in harvesting for the calendar period of harvesting.

If the machine is working on time, but its performance is not sufficient to perform all the work in the optimal time, the losses from crop losses will be:

$$
C y=K x A \times V \times B \times C\left(T_{B^{-}} 1\right) / 2
$$

where $T_{B}$ is the number of hours the machine has been running during this operation.

If there is a replacement combine harvester, the economic losses will be equal to the cost of its labor, with the corresponding deductions for the replacement period.

In animal husbandry, disruptions in terms of animal maintenance (feeding, milking, etc.) due to the absence of an employee due to illness and the lack of substitution also lead to loss of productivity and economic losses. For example, if the feeding time of animals is deviated by 1 hour, their productivity drops by $10.5 \%$. Non-compliance with feeding and 
watering regimes reduces the productivity of the milking herd by $12-18 \%$ or more. Because of this, the secretion is inhibited, the yield is reduced by more than $15-30 \%$.

In addition, the risk of udder inflammation and mastitis increases, due to which milk productivity decreases by $10-40 \%$, the fat content in milk-by $0.15-0.25$, lactose-by $0.4-$ $0.5 \%$, the quality of milk worsens, cases of gynecological diseases become more frequent, animals are prematurely culled.

\section{Accounting for the state economic mechanism for stimulating labor protection}

When calculating the economic efficiency of measures for labor protection and safety, it is methodically correct to take into account the features of state economic mechanisms for stimulating labor protection. If the company has jobs with harmful working conditions, where the employee has the right to early retirement, the employer is obliged to pay insurance premiums to the pension Fund at the appropriate additional rates. This is one of the elements of the mechanism of social protection of employees, but at the same time, an economic lever of pressure on employers, forcing them to bring working conditions to standard. These costs or potential savings in the event of the elimination of such jobs should be taken into account when calculating the cost-effectiveness of occupational safety measures.

Another state economic mechanism for encouraging employers to comply with labor protection requirements is currently the establishment of allowances and discounts.to the insurance rates for compulsory social insurance against accidents at work. The amount of the discount or surcharge can reach $40 \%$ of the insurance rate set for the policyholder. The amount of the discount and surcharge is calculated by the insurer based on the results of the policyholder's activities for the previous calendar year based on the following main indicators:

the ratio of the amount of security payments for insurance in connection with all insured events that occurred for the policyholder to the accrued amount of insurance premiums; number of insured events that occurred for the insured, per thousand employees; the number of days of temporary disability for the policyholder per insured event.

Discounts and surcharges to the policyholder are established by the insurer if the above indicators are less (discount) or more (surcharge) than similar indicators for the industry (sub-industry) that corresponds to the main type of activity of the policyholder. In addition, when calculating the company's economist should not forget about another source of increasing the economic efficiency of labor protection measures. This is a system for returning part of the contributions (up to $20 \%$ ) to the social insurance Fund of the Russian Federation.

\section{Accounting the impact of the level of financial support for labor protection measures on injury rates}

When assessing the risks of accidents and occupational diseases, it is necessary to take into account the level of financial support for labor protection and safety measures. According to the Moscow regional branch of the social insurance Fund of the Russian Federation, the increase in funding, due to the ability to fully implement all necessary measures for labor protection and safety, directly affects the reduction of occupational injuries.

Based on the analysis of the state of traumatism and labor protection costs in agricultural enterprises of the Nizhny Novgorod region, it is established that the number of 
victims of accidents $(\mathrm{Y})$ depends on the level of labor protection costs in agricultural enterprises $(\mathrm{X})$ as follows:

$$
\mathrm{Y}=2,36-0.5333 \mathrm{X}
$$

Based on the results of the correlation analysis, it can be noted that there is a fairly close relationship between the level of injuries and the costs of labor protection measures in agricultural organizations of the Nizhny Novgorod region, and an increase in the cost of labor protection measures per 1 employee by $1 \%$ will lead to a reduction in the level of injuries by 0.53 people per 1,000 employees of the agricultural industry. A new approach to the organization of labor protection for agricultural workers is needed, taking into account the economic efficiency of the planned measures. At the same time, it is necessary to assess both the potential economic damage from injuries and occupational diseases at the enterprise, and the economic effectiveness of measures to improve working conditions and safety.

To understand how big the problem is at a particular enterprise, it is necessary to compare the actual loss of working time at the enterprise ( the number of days per 100 employees) with the estimated amount of losses under favorable working conditions, which is determined by the following formula (Mustafina):

$$
T d=(2.42+0,167 B) 100
$$

where B is the average age of employees, years.

Here it is important to focus on the age of employees, since with working conditions at the enterprise and a signal to carry out a set of preventive measures [15].

Even minor deviations in the employee's well-being can lead to significant economic and social damage. The total amount of damage increases due to an increase in the cost of equipment, an increase in the skills of the worker and, consequently, an increase in the value of working time.

natural age changes and health problems accumulated over many years under the influence of harmful production factors in the workplace significantly increase the loss of working time. If the actual loss of working time is greater than estimated, this is a clear sign of problems.

\section{Conclusion}

Significant costs incurred by agriculture due to the availability of jobs with harmful and dangerous working conditions, it is quite possible to prevent, reducing the risk of accidents, accidents and diseases by eliminating the problems identified during a special assessment of jobs. Moreover, reducing potential risks with a rational approach to possible solutions to problems will allow you to get an economic effect and increase the profitability of agriculture.

Economic services of agricultural enterprises in order to predict possible economic losses due to unfavorable working conditions (the presence of harmful and dangerous production factors) at enterprises, it is necessary to obtain from the labor protection services and use materials for assessing jobs by working conditions and assessing the occupational risks of accidents and occupational diseases of employees of the enterprise. At the same time, receive from the agronomic and zootechnical services of the enterprise an assessment of possible losses of crop and livestock production in case of violation of the agrotechnical deadlines or the rhythm of animal maintenance, depending on the characteristics of the crops and animal breeds used. Based on this information and using the above 
ethodological approach, it is possible to assess possible economic losses due to potential accidents, emergencies or illnesses of employees and the economic effect of the planned costs of labor protection and safety measures.

Employers and labor protection services of agricultural enterprises need to fully implement preventive measures to prevent industrial injuries and occupational diseases, minimize the loss of working time due to colds caused by working conditions, primarily violations of the microclimate parameters in the workplace. To do this, it is necessary to organize the transition to new principles of occupational health and safety management based on the international standards OHSAS 18001:2007 and OIISAS 18002:2008.

It is necessary to make management decisions and conduct organizational work to remove, where possible, the operator's workplaces from the zone of presence of hazards and hazards through remote control and video surveillance systems. Using the principle of managing the time of the operator's presence in the workplace with the presence of hazards and dangers due to the interchangeable movement of employees or increasing the relaxation time in the rooms of psychological relief. It is extremely important to organize regular medical monitoring of the health status of employees of occupational risk groups in order to detect painful changes in a timely manner and take preventive measures at an early stage of an emerging occupational disease.

\section{References}

1. B. Weichelt, S. Gorucu, Injury Prevention, 25(3), 042671 (2017) doi:10.1136/injuryprev-2017-042671. ISSN 1353-8047. PMID 29386372.

2. G. Z. Fainburg, Upravlenets - The Manager, 9(3), 58-65 (2018) DOI: 10.29141/22185003-2018-9-3-10

3. H. van de Vijfeijke., F. R. M. Leijten, J. F. Ybema, S. G. van den Heuvel, S. J. W. Robroek., A. J. van der Beek, et al, J Occup Environ Med, 55(10), 1238-43 (2013) 10.1097/JOM. 0b013e3182a2a5e1. DOI: 10.1097/JOM.0b013e3182a2a5e1

4. De Greef, K. Van den Broek, S. Van Der Heyden, K. Kuhl, E. Schmitz-Felten, Full study report. European Union (2011)

5. S. R. S. Cividino, G. Pergher, R. Gubiani, C. Moreschi, U. Da Broi, M. Vello, F. Rinaldi, Agriculture, 8, 7 (2018)

6. F. R. M. Leijten, S. G. van den Heuvel, J. F. Ybema, A. J. van der Beek, S. J. W. Robroek, A. Burdorf, The influence of chronic health problems on work ability and productivity at work: a longitudinal study among older employees. Scand J Work Environ Health, 40(5), 473-482 (2014) DOI: 10.5271/sjweh.3444.

7. G. Arcangeli, V. Traversini, E. Tomasini, A. Baldassarre, L. I. Lecca, R. P. Galea, N. Mucci, Allergic Anaphylactic Risk in Farming Activities: A Systematic Review. Int. J. Environ. Res. Public Health, 17, 4921 (2020)

8. B. Weichelt, S. Gorucu, Injury Prevention, 25(3), 042671 (2017) doi:10.1136/injuryprev-2017-042671. ISSN 1353-8047. PMID 29386372.

9. E. R. Yagmurov, et al. Journal of Hygienic Engineering and Design, 20, (2017) 60-69

10. I. Zambon, A. Piergentili, L. Salvati, D. Monarca, P. Matyjas-Łysakowska, A. Colantoni, Processes, 6, 87 ( 2018)

11. G. Arcangeli, V. Traversini, E. Tomasini, A. Baldassarre, L. I. Lecca, N. Galea, Int. J. Environ. Res. Public Health, 17, 4921 (2020)

12. M. Fargnoli, M. Lombardi, N. Haber, D. Puri, Agriculture, 8, 82 (2018) 
13. J. Oakman, S. Neupane, K. I. Proper, N. Kinsman, N. Clas-Hakan, Scand J Work Environ Health, 44(2), 134-46 (2018) DOI: 10.5271/sjweh.3685

14. K. Watanabe, T. Tabuchi, N. Kawakami, J Occup, Environ Medicine, 59(3), 295-303 (2017) DOI: 10.1097/JOM.0000000000000950.

15. A. Müller, B. Heiden, B. Herbig, F. Poppe, P. Angerer. J Occup Health Psychol, 21(2), 169-81 (2016) http:// dx.doi.org/10.1037/a0039676. 